\title{
Losing time for the tiger Panthera tigris: delayed action puts a globally threatened species at risk of local extinction
}

\author{
A bishek Harihar, Mousumi Ghosh-Harihar and \\ Douglas C. MacMillan
}

\begin{abstract}
Meeting global and regional environmental targets is challenging, given the multiplicity of stakeholders and their diverse and often competing policy agendas and objectives. Relatively few studies have sought to systematically analyse the progress, or lack thereof, of institutionally complex and diffuse projects. Here we analyse one such project, which aims to protect and restore a critical landscape corridor for tigers Panthera tigris in north-western India, using a temporal-analytic framework that integrates ecological information on species population status and spatial connectivity modelling with a systematic examination of the decision-making process. We find that even with adequate ecological knowledge the tiger population is on the verge of local extinction because of weak institutional support, poor adaptive planning and ineffective leadership in a complex political arena, which has led to delays in conservation action. From the outset the conservation agencies and NGOs that were the primary drivers of the project lacked awareness of the political idiosyncrasies of coordinating the actions of disparate agencies within the decision-making process. To secure better future environmental outcomes we recommend the adoption of an improved project appraisal methodology that explicitly encompasses an evaluation of organizational incentives, to determine political buy-in, including alignment with organizational objectives and funding availability.
\end{abstract}

Keywords Chilla-Motichur, conservation recommendations, corridor connectivity, decision process, implementation, India, multi-stakeholder, western Terai Arc Landscape

Supplementary material for this article can be found at https://doi.org/10.1017/Soo30605317001156

AbisheK Harihar ${ }^{*}$ (Corresponding author) and Douglas C. MacMillan Durrell Institute of Conservation and Ecology, School of Anthropology and Conservation, University of Kent, Kent, CT2 7NZ, UK

E-mail harihar.abishek@gmail.com, aharihar@panthera.org

Mousumi GHosh-Harihar Independent Researcher, Bangalore, Karnataka, India

${ }^{*}$ Also at: Panthera, New York, USA, and Nature Conservation Foundation, Mysore, Karnataka, India

Received 17 February 2017. Revision requested 3 April 2017.

Accepted 21 July 2017. First published online 7 November 2017.

\section{Introduction}

uccessful environmental interventions are often charac$\checkmark$ terized by having clearly defined objectives within a simple institutional framework, such as small-scale woodland creation (e.g. Crabtree et al., 1997; MacMillan et al., 1998). Success stories tend to be relatively straightforward in terms of institutional design and decision-making structure, and are often easy to monitor and assess in terms of their expenditure and the attainment of objectives. Larger scale projects that cross national boundaries or involve a diversity of stakeholders, such as global wildlife trade bans (Ross, 1998) or climate change initiatives such as reduced emissions from deforestation and forest degradation (REDD), are politically and institutionally more complex and diffuse and are prone to failure or stagnation.

There is now considerable interest in reviewing institutionally complex projects to identify general shortcomings and recommendations for better practices (Balmford \& Cowling, 2006; Manolis et al., 2009; Black et al., 2011; Martin et al., 2012), and it is recognized that factors such as strong institutional support, stakeholder buy-in, and effective leadership are critical to their success (Clark et al., 1994; Salafsky et al., 2002). Furthermore, it has been argued that overt and subtle political considerations can often trump robust scientific evidence in multi-actor and multistage decision making in the conservation arena (Kørnøv \& Thissen, 2000).

We use an innovative temporal-analytic framework that integrates spatial connectivity modelling and a systematic approach to decision analysis to investigate the institutional failures that may lead to the imminent local extinction of a tiger Panthera tigris population in the western Terai Arc Landscape of India, a globally important Tiger Conservation Landscape (Sanderson et al., 2006). Tiger conservation is increasingly seen as a global project, with pan-national collaboration anticipated to double tiger numbers by 2022 under the Global Tiger Recovery Program, and we aim to inform the international community about the challenges such initiatives will face.

In this case study we focus on the failure to restore the Chilla-Motichur wildlife corridor, which has deteriorated over the years to the point where, in the western section of the landscape, the tiger population has declined to two female tigers and is no longer viable (Harihar \& Pandav, 
2012). To identify the socio-political factors that imperil this population, we present evidence to demonstrate the decline in tigers and connectivity across the corridor, we review the recommendations provided over the years to mitigate loss in connectivity, and we analyse the decision process involved in implementing these recommendations. We highlight the lessons learnt from this exercise, to guide conservation initiatives aiming to recover tiger populations or similarly threatened species elsewhere.

\section{Study area}

The western Terai Arc Landscape, in addition to supporting one of the highest densities of tigers across its range, presents one of the best opportunities to significantly increase tiger populations in India, with an estimated population increase of $68 \%$ forecast under appropriate management (Harihar et al., 2014). Spanning the Yamuna river in the west to the Gola river in the east, the western Terai Arc Landscape is now split into two disjunct units, referred to as Tiger Habitat Blocks I and II (Johnsingh et al., 2004), with poor connectivity as a result of the deterioration of the Chilla-Motichur corridor, which covers c. $3 \mathrm{~km}^{2}$ along the banks of the river Ganges between the Chilla (eastern banks) and Motichur forest ranges (western banks) of Rajaji Tiger Reserve (Fig. 1). Identified in the early 1980s as a tenuous link for the movement of elephants Elephas maximus (Saxena, 1986), it was also promoted as a critical corridor for tigers in subsequent years (Johnsingh, 2001).

The historical deterioration of connectivity across the corridor may be traced to (1) the expansion of townships (Haridwar and Rishikesh), (2) the resettlement of people displaced by the construction of the Tehri dam and evacuees from landslide-prone areas into several new townships (Khand Gaon I, II \& III and Gangabhogpur), (3) the construction of a hydropower canal on the eastern banks of the Ganges, (4) the establishment of the Raiwala army cantonment on the western banks of the Ganges, and (5) the construction of a National Highway and a railway line, used by an estimated 30,000 motorized vehicles and c. 40 trains per day, respectively (Nandy et al., 2007; Rasaily, 2012).

\section{Methods}

\section{Changes in the status of tigers}

To assess changes in the status of tigers we relied on triangulating our inferences based on three lines of evidence. (1) We assessed changes in the occupancy of tigers across the landscape by comparing surveys conducted in the winters of 2009-2010 (Harihar \& Pandav, 2012) and of 2002-2003 (Johnsingh et al., 2004) in Tiger Habitat Blocks I and II.
(2) We compared an index of tiger sign detections along raus (dry stream beds), based on data from 1995-2010 (S.P. Goyal \& A.J.T. Johnsingh, unpubl. data; B. Pandav \& A. Harihar, unpubl. data), as they were the only comparable data spanning 15 years. (3) We compiled available estimates of tiger density since 2009 .

To assess changes in tiger occupancy in the western Terai Arc Landscape over 7 years, between 2002-2003 (Johnsingh et al., 2004) and 2009-2010 (Harihar \& Pandav, 2012), we compared the data using single-season occupancy models (MacKenzie et al., 2002). In surveys conducted during 2002-2003 (Johnsingh et al., 2004), forest ranges were chosen as the basic sampling units, within multiple-use forest divisions and protected areas, and 3-4 sign surveys, with a mean length of $4 \mathrm{~km}$, were conducted along raus. In all, 105 sign surveys, with a total survey effort of $432.5 \mathrm{~km}$, were carried out across 13 administrative units. During 2009-2010, surveys were conducted with greater intensity across the landscape, using more recent analytical approaches (Harihar \& Pandav, 2012). The survey routes used by Johnsingh et al. (2004) were included so that comparable datasets could be compiled.

For the purpose of this comparative analysis we considered the forest divisions and protected areas as sampling sites' and treated the independent sign surveys as sampling occasions'. Although there has been considerable debate about the substitution of spatial subunits for repeated temporal sampling (Kendall \& White, 2009; Guillera-Arroita, 2011), we assumed that each survey route was independent given their spatial configuration and the wide ranging behaviour of tigers. We constructed eight models each for the 2002-2003 and 2009-2010 survey data, taking into account the influence of Tiger Habitat Blocks (B), indices of wild prey (WildP), principal prey (PrincipP; chital Axis axis and sambar Cervus unicolor) and anthropogenic disturbances (Dist) under the single-season occupancy framework. Our objective was to assess the change in occupancy across 7 years and hence we examined differences in the estimates of the occupancy parameter $(\psi)$ derived from the best-supported models.

Before systematic photographic capture-recapture sampling was used to assess the status of tigers in the western section of Rajaji Tiger Reserve, sign surveys along raus were conducted annually. Data for 1995-2005 were obtained from S.P. Goyal and A.J.T. Johnsingh (unpubl. data), and data for 2007-2010 were obtained from Harihar et al. (2009) and B. Pandav \& A. Harihar (unpubl. data). These surveys were conducted at a rate of $1.25-1.5 \mathrm{~km} \mathrm{~h}^{-1}$ by teams of 2-4 biologists/trainees and assistants and were 3-4 hours in duration. Each transect was divided into $250 \mathrm{~m}$ segments. Indirect evidence of tigers (pug marks, scats and scrapes) was recorded. Based on these data, frequency of occurrence of sign per segment (number of segments with sign/total number of segments surveyed, 

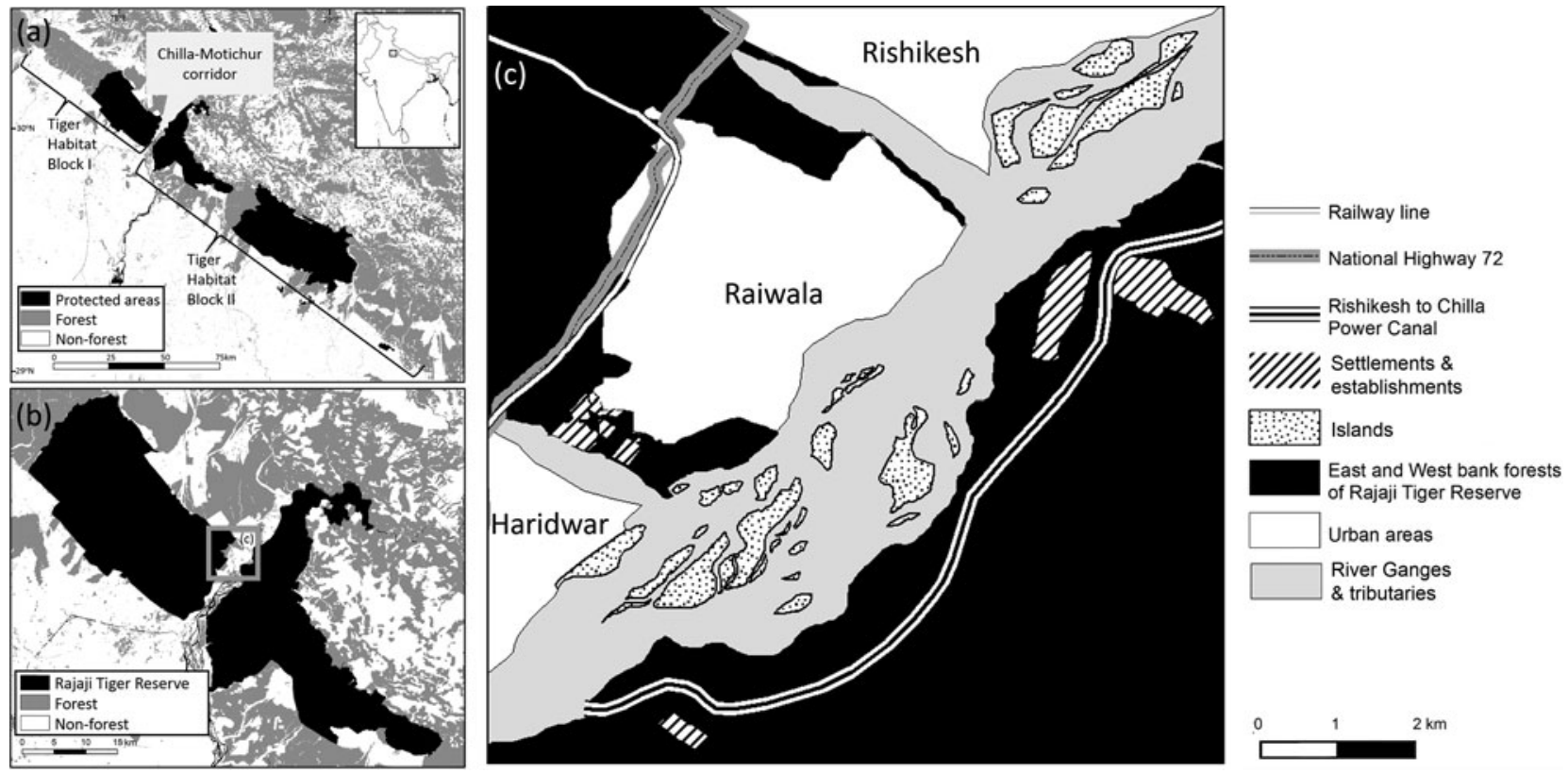

FIG. 1 (a) Location of the Chilla-Mothichur corridor between Tiger Habitat Blocks I and II in the western Terai Arc Landscape of India, (b) the eastern and western parts of Rajaji Tiger Reserve and (c) details of the settlements and infrastructure in the corridor.

expressed as a percentage) was calculated per year, and the trend in population was inferred. We also compiled available estimates of tiger density from systematic photographic capture-recapture studies carried out since 2009 (Harihar \& Pandav, 2012; Rathore, 2015; B. Pandav \& A. Harihar, unpubl. data).

\section{Changes in connectivity}

The loss of connectivity between Tiger Habitat Blocks I and II is primarily a result of the expansion of Haridwar, Rishikesh and Raiwala townships, and several infrastructural projects. During $1972-1995$ an estimated $11.18 \mathrm{~km}^{2}$ of forest in the Chilla-Motichur corridor was lost (Nandy et al., 2007). Although tigers disperse from their natal ranges over great distances through a range of forested habitats, agricultural lands and areas of low human population density, they are known to avoid urban areas (Smith, 1993; Joshi et al., 2013; Singh et al., 2013). We used remotely sensed data on night-time lighting as an indicator of urbanization (Henderson et al., 2003), to evaluate changes in connectivity across the corridor during 1993-2013. We obtained the radiance calibrated data, at a spatial resolution of 30 arc second grid cells $\left(\right.$ c. $\left.1 \mathrm{~km}^{2}\right)$, for 1993, 2003 and 2013 from the National Geophysical Data Centre (NOAA, 2017). Higher radiance indicates areas of urbanization (i.e. areas through which tigers are less likely to move). The annual mean brightness level in units of 6-bit digital numbers spanning o-63 were used as resistance values in the analysis. To assess the potential changes in connectivity between the two Tiger Habitat Blocks over time, we used circuit theory (McRae et al., 2008) implemented in Circuitscape v. 4 (McRae et al., 2013). We designated the western and eastern parts of Rajaji Tiger Reserve (in Tiger Habitat Blocks I and II, respectively) as nodes in our models, and identified multiple paths of potential connectivity between the nodes using the pair-wise algorithm. We produced cumulative current flow maps for visual representation, and summarized the mean current flow values (a measure of connectivity) for the corridor across the three time periods (1993, 2003 and 2013).

\section{Decision analysis}

Clark \& Brunner (2002) described a decision process that typically comprises seven functions (intelligence, promotion, prescription, invocation, application, appraisal and termination; see definitions in Table 1) that seeks to identify and reconcile any conflicts among policies relating to the implementation of a species recovery programme involving complex partnerships, and minimize the risk of failure. We follow this approach and identify these seven functions in each recommendation given for restoring the ChillaMotichur corridor, a multi-institutional endeavour, and ascertain the stages at which delay/divergence occurred in the implementation process. Through this analysis we identify the agencies responsible for carrying out the action, with the objective of identifying the functions where intervention was required to strengthen the partnerships and improve the process of recovery.

Our data are primarily from academic/official publications concerning conservation recommendations for the Chilla-Motichur corridor, covering the period 1986-2016. 
TABLE 1 Assessment of decision functions that delayed various conservation actions in the Chilla-Motichur corridor, in India's western Terai Arc Landscape (Fig. 1).

\begin{tabular}{|c|c|c|c|c|c|c|c|}
\hline & Definition $^{*}$ & Activities $^{*}$ & $\begin{array}{l}\text { Resettlement of } \\
\text { Khand Gaon III }\end{array}$ & $\begin{array}{l}\text { Resettlement of } \\
\text { army ammunition } \\
\text { dump }\end{array}$ & $\begin{array}{l}\text { Strengthen law } \\
\text { enforcement on } \\
\text { river islands }\end{array}$ & $\begin{array}{l}\text { Construction of } \\
\text { vehicular flyover }\end{array}$ & $\begin{array}{l}\text { Supplementation of } \\
\text { tigers to western RNP }\end{array}$ \\
\hline Intelligence & Planning & $\begin{array}{l}\text { Relevant information is gathered, processed \& } \\
\text { distributed; project is planned \& goals are } \\
\text { defined (e.g. field work, social surveys, } \\
\text { simulations) }\end{array}$ & $\sqrt{ }$ & $\sqrt{ }$ & $\sqrt{ }$ & $\sqrt{ }$ & $\sqrt{ }$ \\
\hline Promotion & Open debate & $\begin{array}{l}\text { Active advocacy \& debate about various al- } \\
\text { ternatives; resources, data \& opinions are } \\
\text { mobilized (e.g. pluralistic discussions, forums) }\end{array}$ & $\sqrt{ }$ & $\sqrt{ }$ & $\sqrt{ }$ & $\sqrt{ }$ & $\sqrt{ }$ \\
\hline Prescription & $\begin{array}{l}\text { Setting rules/ } \\
\text { guidelines }\end{array}$ & $\begin{array}{l}\text { Policies \& guidelines are formulated \& } \\
\text { enacted; these must be communicated \& } \\
\text { approved by concerned implementing agen- } \\
\text { cies (e.g. recovery plans, habitat/species man- } \\
\text { agement plans) }\end{array}$ & $\sqrt{ }$ & & $\sqrt{ }$ & $\sqrt{ }$ & $\sqrt{ }$ \\
\hline Invocation & Implementation & $\begin{array}{l}\text { Application of rules/guidelines to actual cases } \\
\text { (initiation of programmes, constitution of } \\
\text { teams \& beginning of work in field \& offices) }\end{array}$ & $\sqrt{ }$ & & & $\sqrt{ }$ & \\
\hline Application & $\begin{array}{l}\text { Dispute } \\
\text { resolution }\end{array}$ & $\begin{array}{l}\text { Deviation from initial rules/guidelines re- } \\
\text { solved through enforcement \& constant re- } \\
\text { view to allow implementation to continue. } \\
\text { (e.g. internal or external (court) forums may } \\
\text { feature) }\end{array}$ & $\sqrt{ }$ & & & $\sqrt{ }$ & \\
\hline Appraisal & Review & $\begin{array}{l}\text { Efforts are evaluated through continuous ap- } \\
\text { praisal, - in terms of goal achievement \& ac- } \\
\text { countability (e.g. internal \& external reviews) }\end{array}$ & & & & & \\
\hline Termination & Conclusion & $\begin{array}{l}\text { Cancelling past prescriptions as they have ei- } \\
\text { ther been implemented or failed, \& compen- } \\
\text { sating people affected }\end{array}$ & & & & & \\
\hline
\end{tabular}

${ }^{\star}$ As provided in Clark \& Brunner (2002) 
We initially identified relevant articles from screening the bibliography of Uniyal et al. (2006), and updated these data by searching ISI Web of Science and Google Scholar. In addition to journal articles and book chapters we searched for non peer-reviewed reports, as many recommendations are communicated through such reports to the relevant implementing agencies. Initially we searched for all articles that included the terms 'Chilla-Motichur', 'Chilla Motichur' or 'Chilla-Motichur corridor' in the title, keywords or abstract. Only articles that focused on the corridor and provided recommendations regarding its restoration were retained for analysis. Furthermore, AH interviewed scientists and bureaucrats engaged with the project, in person or via e-mail, to learn about their experiences and obtain updates about the status of the recommendations. We focus only on those recommendations that have been adopted in government plans.

\section{Results}

\section{Decline in tigers}

All three lines of evidence confirmed a decline in tiger numbers in Tiger Habitat Block I. The occupancy analysis indicated there had been a $58 \%$ reduction in occupancy between the two sampling sessions (Fig. 2a; Supplementary Tables S1$S_{3}$ ). In contrast, in Tiger Habitat Block II there was an increase in occupancy, primarily as a result of the recovery of tigers in eastern Rajaji Tiger Reserve (Fig. 2a; Supplementary Fig. S1; Supplementary Tables $\mathrm{S}_{1}-\mathrm{S}_{3}$ ).

The annual frequency of occurrence of tiger sign per segment indicated a declining trend in the western part of the Reserve (Fig. 2b). During 1995-1998 tiger sign was recorded on c. $30-38 \%$ of the surveyed segments. However, during $2007-2010$ tiger sign was recorded on only $8 \%$ of surveyed segments.

Available estimates of tiger density from systematic photographic capture-recapture sampling conducted across the western part of the Reserve since 2009 indicated the presence of a low-density population of $0.28-0.4$ tigers per $100 \mathrm{~km}^{2}$ during 2009-2015 (Supplementary Table S4; Harihar et al., 2009; Rathore, 2015; Pandav \& Harihar, unpubl. data).

\section{Deterioration of habitat in the corridor}

Our analysis indicates that since 1993 the opportunity to reconnect tiger subpopulations across the Chilla-Motichur corridor has diminished rapidly (Supplementary Fig. S2). Current flow (a measure of connectivity) across the corridor, estimated through the Circuitscape analysis, decreased progressively and significantly from 1.98 amps (95\% CI $1.92-2.03)$ in 1993 to 1.73 amps (1.67-1.78) in 2003 and 1.25 amps $(1.21-1.28)$ in 2013. The formation of the state of
Uttarakhand (in 2000) and the associated economic growth have led to rapid urbanization in the corridor area, and increasing demand on natural resources (Mamgain, 2007). This habitat deterioration indicates a loss of functional connectivity for tigers.

\section{Decision analysis}

We collated 31 articles from 1986-2016 that met our search criteria: 14 peer-reviewed journal articles and 17 non peerreviewed reports/articles (Supplementary Table S5). Only 20 of these provided specific recommendations to restore connectivity across the Chilla-Motichur corridor, and a review of these indicates a general timeline of recommendations (Fig. 3). Connectivity across the river Ganges between the Chilla (eastern bank) and Motichur (western bank) forest ranges was recognized as being tenuous in the 1980s, particularly with respect to the movement of elephants (Saxena, 1986). In later years conservationists reiterated the need for recovery of this patch so that it could function as a critical corridor for tigers between Tiger Habitat Blocks I and II (Johnsingh et al., 2004). Eventually, as the prospect of recovering this patch faded, conservationists subsequently recommended translocation of a breeding male from Tiger Habitat Block II to the western part of the Reserve so that the remaining females could breed (Harihar \& Goyal, 2010), a recommendation that has yet to be acted upon (Fig. 3). Thus, intelligence has been provided and updated on an ongoing basis to support critical actions required to ensure the persistence of tigers across the two halves of the Reserve.

Overall, the recommendations of conservation scientists provided the broader conservation goals but did not adequately consider the social (e.g. resettlement of Khandgaon III) and political difficulties (relocation of an army ammunition dump) that would be encountered in pursuing these recommendations (Fig. 3). Of the 14 recommendations provided to restore connectivity across the corridor, only five have been promoted and incorporated into government management and operational plans (Rasaily, 2012; NTCA, 2015), following years of discussion and debate between the partnering agencies to resolve conflicting policies or interests (Fig. 3). Prescribing the recommendations into specific guidelines and actions also required considerable time, as it often necessitated external expertise beyond ecological knowledge of the system. For instance, the recommendation to relocate the ammunition dump needed prescriptions for significant bureaucratic negotiations between the state forest department and Ministry of Defence, and the construction of a flyover was contingent on civil engineering solutions (Fig. 3). For the two recommendations for which implementation was initiated (i.e. resettlement of Khandgaon III and construction of a flyover), the process was delayed by difficulties in mobilizing funds and approvals from concerned state departments, and 

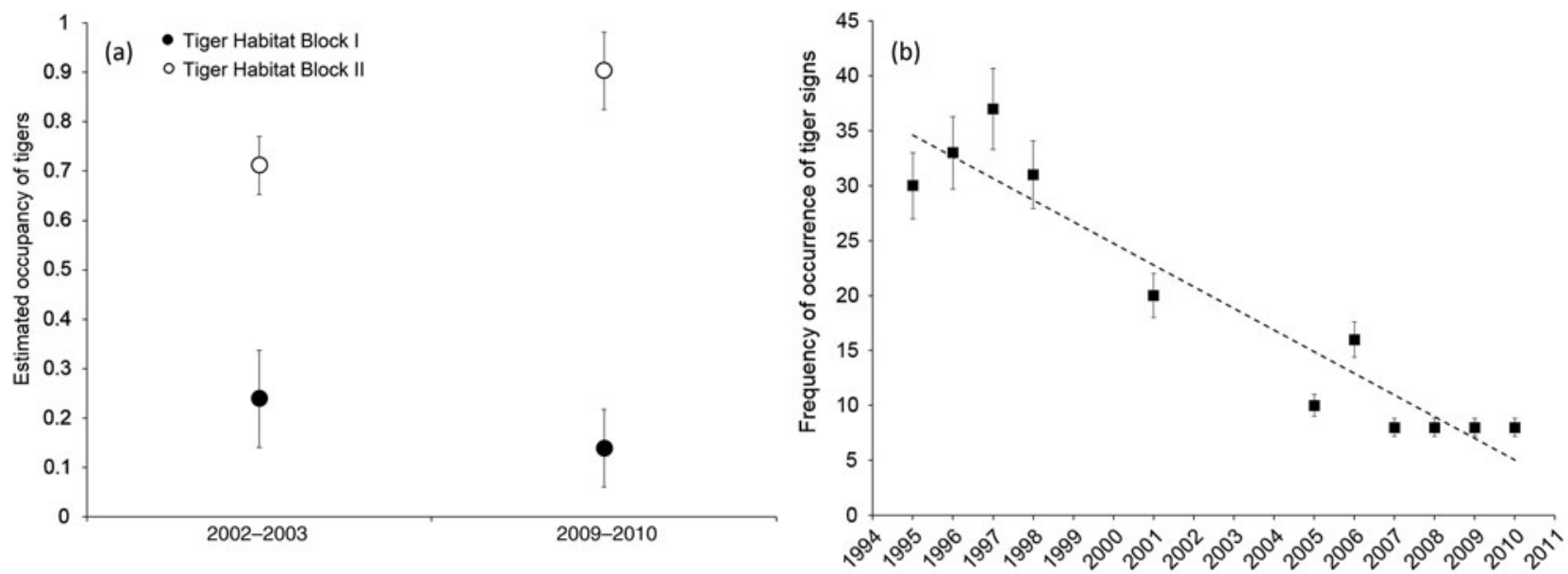

FIG. 2 (a) The estimated occupancy of tigers Panthera tigris in Tiger Habitat Blocks I and II (Fig. 1) during 2002-2003 and 2009-2010, indicating a decline in Tiger Habitat Block I and an increase in Tiger Habitat Block II. (b) Frequency of detection of tiger sign per $250 \mathrm{~m}$ segment of transect in the western part of Rajaji National Park during 1995-2010. Error bars indicate 95\% CI.

irregularities in following guidelines for construction, respectively (Fig. 3). In the case of supplementation of tigers, lack of adequate federal funds and political will prevented this prescription from being implemented. Managers are hesitant to implement such a potentially risky action, given that demonstrable population increases post translocation may not happen during their tenure (VanderWerf et al., 2006).

Other critical shortcomings included the lack of a clear timeline for each action, and the lack of provision for followup actions and evaluation based on a monitoring protocol within an adaptive management framework should difficulties arise in the implementation (Wilhere, 2002). In the end the only recommendation that was implemented, in 2015, was the resettlement of Khandgaon III village, although the process took 26 years (Fig. 3).

\section{Discussion}

The case of the Chilla-Motichur corridor has been described as an acid-test for the Indian conservation movement (Johnsingh et al., 2004), and despite the reiteration of recommendations to recover this habitat over nearly 3 decades, the population of tigers at their north-western range limit remains threatened with almost imminent extinction. We found that despite the availability of adequate and timely ecological information and assessment, the project has failed to make progress as a result of multiple institutional failings related to communication and promotion of recommended actions, the lack of responsive governance, ineffective leadership and minimal institutional accountability.

Given that almost all the recommendations required collaboration amongst various organizations with different remits and priorities, the long delays in the initial stages (promotion and prescription) could perhaps have been avoided if a multidisciplinary team had been established at the outset to mobilize resources, identify alternative actions and prescribe the recommendations into specific guidelines and/or actions, with expertise not only in species ecology but in the management of human dimensions in the corridor. Such a multidisciplinary partnership has been instrumental in recovering the eastern barred bandicoot Perameles gunnii (Backhouse et al., 1994).

Even after prescription, resettlement of Khandgaon III was delayed as the state departments involved struggled to secure adequate funding and collaborate efficiently to implement the identified policies, in a case of diverse mandates meeting layers of official bureaucracy (Fig. 3). Political power play, in which a department of greater strategic interest (e.g. Ministries of Transport and Defence) refuses to make a concession for the requirements of a relatively local issue, was also evident, as is typical of scenarios in which networking and political compromises determine conservation outcomes (Kørnøv \& Thissen, 2000; Lochner et al., 2003). A key characteristic common to all these delayed actions is that decision making rested within large government agencies with complex and multi-layered bureaucratic structures (Table 2), which made it easy to evade accountability (Wallace et al., 1994; Martin et al., 2012), especially when dealing with long-term conservation goals. Decision makers in government agencies can change frequently; for example, the civil servants who head the management of Rajaji Tiger Reserve change every 5 years.

Effective leadership is of critical importance in recovery efforts for threatened species, to mobilize necessary expert and public participation under one body, garner adequate resources, gain acceptance from relevant government agencies and local communities, champion the cause and take responsibility to effect change in a timely manner (Black \& Groombridge, 2010; Martin et al., 2012). In our case study the primary responsibility for implementing the recommendations rested with multiple agencies within the state forest department, with no clear leadership to ensure 


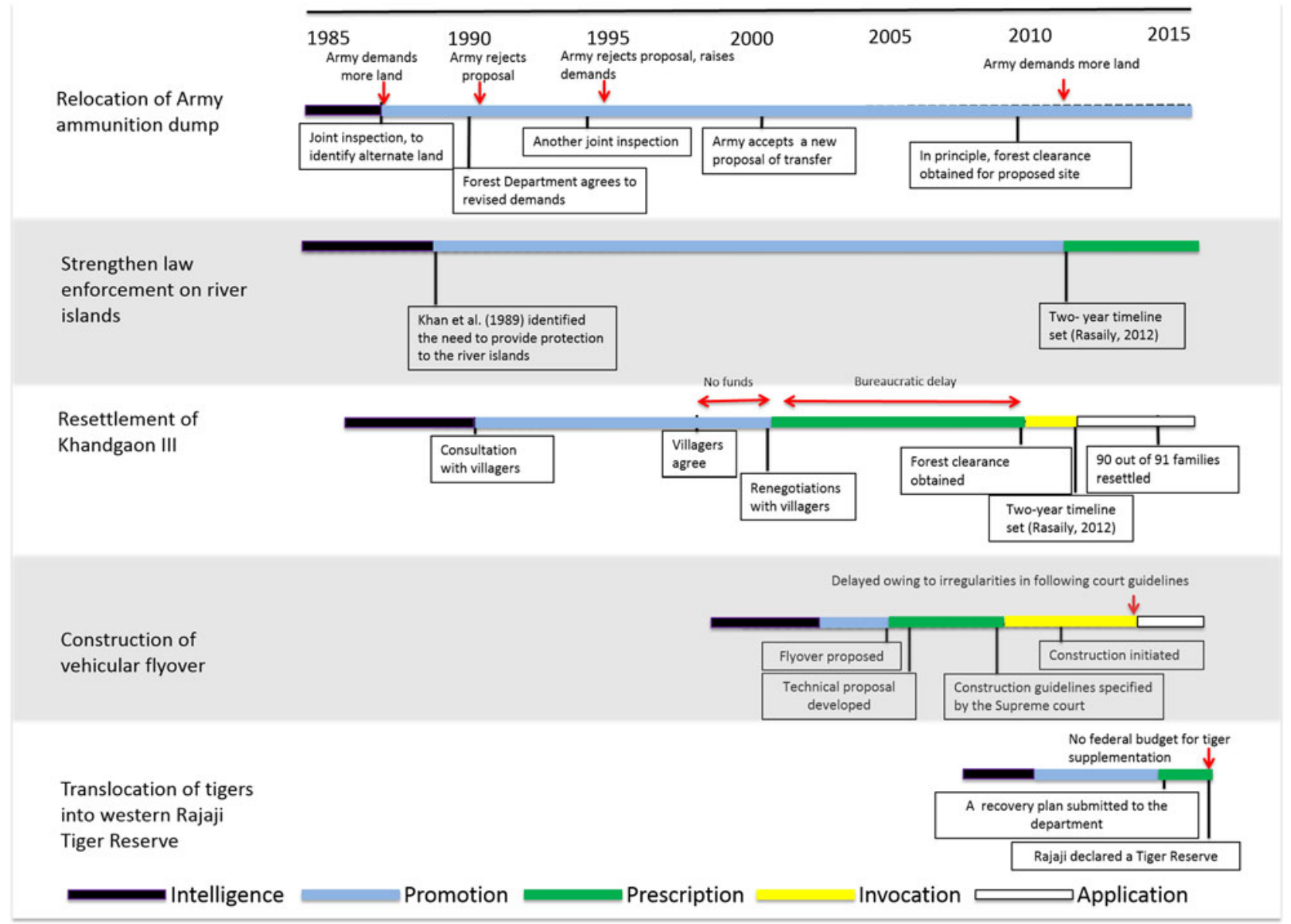

FIG. 3 A timeline for the implementation of key recommendations to restore the Chilla-Mothichur corridor between the western and eastern sectors of Rajaji Tiger Reserve in the western Terai Arc Landscape of India (Fig. 1). Specific actions are outlined within boxes, critical obstacles are denoted by arrows, and the decision functions (following Clark \& Brunner, 2002) are denoted by the colour scheme defined in the legend. For more details regarding the process see Supplementary Material 1.

that the decision process was implemented in a timely and appropriate manner (Table 2). Moreover, given that many political aspects were clearly not within the programme's sphere of control and were beyond the influence of the primary implementing agencies, effective and flexible leadership was essential to address the constantly changing needs and threats and adapt actions, while focusing on a stable long-term vision to guide the work of the programme (Maris \& Béchet, 2010). Policy czars are widely used in the USA and UK to oversee complex policy reforms that involve multiple government departments, and reach out to multiple stakeholders; these czars cannot be side-lined by selfinterested groups as they report to only the highest levels of authority. Such figures may be rare, but conservation could benefit from a better appreciation of leadership. Project designers should bear in mind the need to discuss project objectives and implementation with key stakeholders, and adjust objectives to suit practical and political concerns, perhaps through the adoption of decision-making analysis such as the Delphi approach (MacMillan \& Marshall, 2006).
Furthermore, with no adaptive management framework in place, nor any approach to ensure accountability amongst government agencies, this case illustrates the need for conservation programmes to be conceived and managed within a so-called business excellence model (Black \& Groombridge, 2010). This would ensure greater clarity in defining objectives, setting goals, delineating the roles of leaders and staff, identifying success measures and feedback data, creating better links between technical approaches and measures of biological success, community engagement, more effective use of resources, and the establishment of management reviews. In establishing such a system it is critical to develop a good logic model and results chain through the participation of all major stakeholders from the initial stages of any conservation intervention (FOS, 2009; Margoluis et al., 2013).

The creation and/or restoration of resilient landscape corridors for free-roaming mega-fauna may be an unrealistic goal unless appropriate funding and intervention mechanisms, such as a cost-effective compensation payment scheme or more novel approaches such as certification or payment 
TABLE 2 The partners associated with the implementation of each of the recommendations for the conservation of the Chilla-Motichur corridor, in India's western Terai Arc Landscape (Fig. 1), and their specific roles.

\begin{tabular}{|c|c|c|c|c|c|c|}
\hline Partners & Role $^{\star}$ & $\begin{array}{l}\text { Resettlement of } \\
\text { Khandgaon } \\
\text { III }\end{array}$ & $\begin{array}{l}\text { Resettlement of } \\
\text { army ammunition } \\
\text { dump }\end{array}$ & $\begin{array}{l}\text { Strengthen law } \\
\text { enforcement } \\
\text { on river islands }\end{array}$ & $\begin{array}{l}\text { Construction } \\
\text { of vehicular } \\
\text { flyover }\end{array}$ & $\begin{array}{l}\text { Supplementation } \\
\text { of tigers to western } \\
\text { Rajaji National Park }\end{array}$ \\
\hline Management of Rajaji National Park/Tiger Reserve & Primary implementation agency & $\sqrt{ }$ & $\sqrt{ }$ & $\sqrt{ }$ & $\sqrt{ }$ & $\sqrt{ }$ \\
\hline $\begin{array}{l}\text { Management of Territorial Forest Department } \\
\text { (resettlement/relocation site) }\end{array}$ & Primary implementation agency & $\sqrt{ }$ & $\sqrt{ }$ & & & \\
\hline State Department of Environment \& Forests & Primary implementation agency & $\sqrt{ }$ & $\sqrt{ }$ & & $\sqrt{ }$ & $\sqrt{ }$ \\
\hline $\begin{array}{l}\text { Ministry of Environment \& Forests, } \\
\text { Government of India }\end{array}$ & Secondary implementation agency & $\sqrt{ }$ & $\sqrt{ }$ & & $\sqrt{ }$ & $\sqrt{ }$ \\
\hline State Administrative Services & Secondary implementation agency & $\sqrt{ }$ & & & & \\
\hline District Administration & Secondary implementation agency & $\sqrt{ }$ & & & & \\
\hline Ministry of Defence, Government of India & Implementation facilitators & & $\sqrt{ }$ & & & \\
\hline $\begin{array}{l}\text { Ministry of Road Transport \& Highways, } \\
\text { Government of India }\end{array}$ & Implementation facilitators & & & & $\sqrt{ }$ & \\
\hline Local people & Implementation facilitators & $\sqrt{ }$ & & & & \\
\hline National Board for Wildlife & Regulatory authority & & & & $\sqrt{ }$ & \\
\hline Central Empowered Committee, Supreme Court & Regulatory authority & & & & $\sqrt{ }$ & \\
\hline National Tiger Conservation Authority & Regulatory authority & & & & & $\sqrt{ }$ \\
\hline $\begin{array}{l}\text { Research Institutes (e.g. Wildlife Institute of India, } \\
\text { Indian Institute of Remote Sensing) }\end{array}$ & Research \& intelligence & $\sqrt{ }$ & $\sqrt{ }$ & $\sqrt{ }$ & $\sqrt{ }$ & $\sqrt{ }$ \\
\hline Local NGOs & $\begin{array}{l}\text { Research \& intelligence provider, } \\
\text { implementation support }\end{array}$ & $\sqrt{ }$ & $\sqrt{ }$ & & $\sqrt{ }$ & $\sqrt{ }$ \\
\hline
\end{tabular}

*Primary implementation agency: directly accountable agency with the mandate to conserve wildlife; Secondary implementation agency: facilitate the implementation process through policy and logistic/funding support, but not directly accountable; Implementation facilitators: stakeholders/agencies whose consent and cooperation is indispensable to implementation; Regulatory authority: oversee the process, lay guidelines and resolve any conflicts; Research \& intelligence: these NGOs provide the primary evidence and recommendations, and may also provide logistic support for implementation 
for ecosystem services schemes, are tied to a bottom-up needs-based development assessment (Harihar et al., 2015). Only then can such projects appeal to all types of land managers, owners and users, who may not share common objectives, land rights or motivations with either their neighbours or the main project stakeholders (MacMillan \& Phillip, 2010; Davies \& White, 2012; Redpath et al., 2013). The entire process of corridor designation could be more efficient if all these factors are synchronized (Brodie et al., 2015).

We have shown how institutional failings caused by uncoordinated policies and actions and perverse decision making, despite awareness of critical ecological knowledge, have conspired to create an imminent extinction crisis for a remnant tiger population in India. The opportunity to restore the Chilla-Motichur corridor seems to be disappearing rapidly, but future conservation projects must pay closer attention to institutional issues that arise from local social, political and economic opportunities and concerns. Simultaneously, they must inherently recognize and address the political idiosyncrasies of the local and national agencies, which are differentially motivated and can easily succumb to self-serving actions, within the decision process.

A key recommendation from our research is the need to develop adaptive conservation plans with effective leadership and funding to secure stakeholder buy-in. The old unicentric model of conservation, in which central decision makers would steer and implement the process, guided by rational use of scientific evidence in a sequential fashion, is no longer appropriate to meet the challenges of a fastchanging and increasingly complex world. The adoption of a polycentric model, in which decisions rest in the hands of multiple independent agencies and outcomes are driven by compromises, available means, political support and power play in an unpredictable fashion, rather than by objective knowledge, may require a cultural shift and a rethink of how conservationists engage with the nonconservation world.

We recommend that greater research effort be invested in understanding decision-making processes in complex conservation projects. Of central importance is the need to recognize that decision making is a process rather than an event, involving a sequence of decisions defined by rules, which seek to reconcile policy differences between multiple stakeholders with differing and conflicting motivations. We believe that a firmer understanding of decision-making science, and investment in this discipline, could generate considerable benefits for biodiversity.

\section{Postscript}

In June 2017 the National Tiger Conservation Authority allocated a budget of INR 34 million (USD 500,000) for translocating tigers into Rajaji Tiger Reserve. It is now expected that five tigers will be translocated in the winter of 2017-2018 to supplement the existing population and assist its recovery (Thapliyal, 2017).

\section{Acknowledgements}

We thank A.J.T Johnsingh, S.P. Goyal and Bivash Pandav for helping us at various stages in the preparation of this manuscript. This study was supported in part by grants from Kaplan Graduate Awards (Panthera), Kathryn Fuller Science for Nature Fellowships (WWF) and the Rufford Small Grants Foundation (Grant 10691-2) to AH.

\section{Author contributions}

$\mathrm{AH}, \mathrm{MG}-\mathrm{H}$ and DCM conceived the study and wrote and edited the article. AH and MG-H collected and analysed the data.

\section{References}

Backhouse, G.N., Clark, T.W. \& Reading, R.P. (1994) The Australian eastern barred bandicoot recovery program: evaluation and reorganization. In Endangered Species Recovery: Finding the Lessons, Improving the Process (eds T.W. Clark, R.P. Reading \& A.L. Clarke), pp. 251-274. Island Press, Washington, DC, USA.

BADOLA, R. (1993) WII's research inputs in U.P. Siwaliks with special reference to elephant conservation. In Abstracts: Seventh Annual Research Seminar, p. 13. Wildlife Institute of India, Dehradun, India. BAlmford, A. \& Cowling, R.M. (2006) Fusion or failure? The future of conservation biology. Conservation Biology, 20, 692-695.

Black, S.A. \& Groombridge, J.J. (2010) Use of a business excellence model to improve conservation programs. Conservation Biology, 24, 1448-1458.

Black, S.A., Groombridge, J.J. \& Jones, C.G. (2011) Leadership and conservation effectiveness: finding a better way to lead. Conservation Letters, 4, 329-339.

Brodie, J.F., Giordano, A.J., Dickson, B., Hebblewhite, M., Bernard, H., Mohd-Azlan, J. et al. (2015) Evaluating multispecies landscape connectivity in a threatened tropical mammal community. Conservation Biology, 29, 122-132.

Clark, T.W. \& Brunner, R.D. (2002) Making partnerships work in endangered species conservation: an introduction to the decision process. Endangered Species Update, 19, 74-80.

Clark, T.W., Reading, R.P. \& Clarke, A.L. (eds) (1994) Endangered Species Recovery: Finding the Lessons, Improving the Process. Island Press, Washington, DC, USA.

Crabtree, J.R., Bayfield, N., Chalmers, N.A. \& MacMillan, D.C. (1997) A socio-economic and environmental appraisal of the Farm Woodland Premium Scheme in Scotland. Scottish Forestry, 51, 84-91.

Davies, A.L. \& White, R.M. (2012) Collaboration in natural resource governance: reconciling stakeholder expectations in deer management in Scotland. Journal of Environmental Management, $112,160-169$.

FOS (Foundations of Success) (2009) Using results chains to improve strategy effectiveness: an FOS how-to guide. Http://www. fosonline.org/resource/using-results-chains [accessed 2 August 2017]. 
Ghosh, P.K. (2003) Local NGO movement for conservation of the Chilla-Motichur corridor. In Securing the Chilla Motichur Corridor: A Status Report (eds V. Menon, P. Easa \& A.J.

T. Johnsingh), pp. 34-35. Wildlife Trust of India, New Delhi, India.

Guillera-Arroita, G. (2011) Impact of sampling with replacement in occupancy studies with spatial replication. Methods in Ecology and Evolution, 2, 401-406.

Harihar, A. \& Goyal, S.P. (2010) Population and Habitat Viability of Tiger Subpopulations in the North-Western Terai Arc Landscape. Wildlife Institute of India, Dehradun, India.

HARIHAR, A. \& PANDAv, B. (2012) Influence of connectivity, wild prey and disturbance on occupancy of tigers in the human-dominated western Terai Arc Landscape. PLoS ONE, 7(7), e40105.

Harihar, A., Pandav, B. \& MacMillan, D.C. (2014) Identifying realistic recovery targets and conservation actions for tigers in a human-dominated landscape using spatially explicit densities of wild prey and their determinants. Diversity and Distributions, 20, 567-578.

Harihar, A., Prasad, D.L., Ri, C., Pandav, B. \& Goyal, S.P. (2009) Losing ground: tigers Panthera tigris in the north-western Shivalik landscape of India. Oryx, 43, 35-43.

Harihar, A., Veríssimo, D. \& MacMillan, D.C. (2015) Beyond compensation: integrating local communities' livelihood choices in large carnivore conservation. Global Environmental Change, 33, 122-130.

Henderson, M., Yeh, E.T., Gong, P., Elvidge, C. \& Baugh, K. (2003) Validation of urban boundaries derived from global night-time satellite imagery. International Journal of Remote Sensing, 24, 595-609.

Johnsingh, A.J.T. (2001) Establishment of Chilla-Motichur corridor for elephant and tiger movement. WII Newsletter, 8, 1-3.

Johnsingh, A.J.T. (2003) The need for the establishment of the Chilla-Motichur corridor for elephant and tiger movement. In Securing the Chilla-Motichur Corridor: A Status Report (eds V. Menon, P. Easa \& A.J.T. Johnsingh), pp. 22-35. Wildlife Trust of India, New Delhi, India.

Johnsingh, A.J.T. (2006) Status and conservation of the tiger in Uttaranchal, northern India. Ambio, 35, 135-137.

Johnsingh, A.J.T. \& JoshuA, J. (1994) Conserving Rajaji and Corbett National Parks-the elephant as a flagship species. Oryx, 28, 135-140.

Johnsingh, A.J.T. \& Madhusudan, M.D. (2009) Tiger reintroduction in India: conservation tool or costly dream? In Reintroduction of Top-Order Predators (eds M.W. Hayward \& M. Somers), pp. 146-163. Blackwell Publishing, Chichester, UK.

Johnsingh, A.J.T. \& Negi, A.S. (2003) Status of tiger and leopard in Rajaji-Corbett Conservation Unit, northern India. Biological Conservation, 111, 385-393.

Johnsingh, A.J.T., Prasad, S.N. \& Goyal, S.P. (1990) Conservation status of the Chila-Motichur corridor for elephant movement in Rajaji-Corbett National Parks area, India. Biological Conservation, $51,125-138$.

Johnsingh, A.J.T., Qureshi, Q., Mohan, D.M. \& Williams, A.C. (2003) The north-western elephant range. In Securing the ChillaMotichur Corridor: A Status Report (eds V. Menon, P. Easa \& A.J. T. Johnsingh), pp. 7-21. Wildlife Trust of India, New Delhi, India.

Johnsingh, A.J.T., Ramesh, K., Qureshi, Q., David, A., Goyal, S., RAwAT, G. et al. (2004) Conservation Status of Tiger and Associated Species in the Terai Arc Landscape, India. Wildlife Institute of India, Dehradun, India.

Johnsingh, A.J.T. \& Williams, A.C. (1999) Elephant corridors in India: lessons for other elephant range countries. Oryx, 33, 210-214. Joshi, A., Vaidyanathan, S., Mondol, S., Edgaonkar, A. \& Ramakrishnan, U. (2013) Connectivity of tiger (Panthera tigris) populations in the human-influenced forest mosaic of central India. PLOS ONE, 8(11), e77980.

Joshi, R. (2015) Tusker's social bonds in Rajaji. Hystrix, The Italian Journal of Mammalogy, 26, 41-45.

Joshi, R. (2016) Rajaji Tiger Reserve: conservation opportunities and challenges. Current Science, 110, 959-960.

Joshi, R. \& SinGH, R. (2007) Asian elephants are losing their seasonal traditional movement tracks: a decade of study in and around the Rajaji National Park, India. Gajah, 27, 15-26.

Joshi, R. \& Singh, R. (2008) Asian elephant (Elephas maximus) and riparian wildlife corridors: a case study from lesser-Himalayan zone of Uttarakhand. The Journal of American Science, 4, 63-75.

Joshi, R., Singh, R. \& Rishikesh, D. (2009) Wildlife corridors and Asian elephants (Elephas maximus): lessons from Rajaji National Park, north-west India. Journal of American Science, 5, 31-40.

Jumani, S., RaO, S., Machado, S. \& Prakash, A. (2017) Big concerns with small projects: evaluating the socio-ecological impacts of small hydropower projects in India. Ambio, 46, 500-511.

Kendall, W.L. \& White, G.C. (2009) A cautionary note on substituting spatial subunits for repeated temporal sampling in studies of site occupancy. Journal of Applied Ecology, 46, 1182-1188.

Khan, A., Johnsingh, A.J.T., Chowdhary, S. \& Sale, J.B. (1989) Report on Rajaji Project, March 1987-December 1988. Wildlife Institute of India, Dehradun, India.

Kørnøv, L. \& Thissen, W.A.H. (200o) Rationality in decision- and policy-making: implications for strategic environmental assessment. Impact Assessment and Project Appraisal, 18, 191-200.

Lochner, P., Weaver, A., Gelderblom, C., Peart, R., Sandwith, T. \& Fowkes, S. (2003) Aligning the diverse: the development of a biodiversity conservation strategy for the Cape Floristic Region. Biological Conservation, 112, 29-43.

MacKenzie, D.I., Nichols, J.D., Lachman, G.B., Droege, S., Royle, J.A. \& Langtimm, C.A. (2002) Estimating site occupancy rates when detection probabilities are less than one. Ecology, 83, 2248-2255.

MacMillan, D.C., Harley, D. \& Morrison, R. (1998) Cost-effectiveness analysis of woodland ecosystem restoration. Ecological Economics, 27, 313-324.

MacMillan, D.C. \& Marshall, K. (2006) The Delphi process-an expert-based approach to ecological modelling in data-poor environments. Animal Conservation, 9, 11-19.

MacMillan, D.C. \& Phillip, S. (2010) Can economic incentives resolve conservation conflict: the case of wild deer management and habitat conservation in the Scottish highlands. Human Ecology, 38, 485-493.

Mamgain, R.P. (2007) Growth, Poverty and Employment in Uttarakhand. Institute for Human Development, New Delhi, India.

Manolis, J.C., Chan, K.M., Finkelstein, M.E., Stephens, S., Nelson, C.R., Grant, J.B. \& Dombeck, M.P. (2009) Leadership: a new frontier in conservation science. Conservation Biology, 23, 879-886.

Margoluis, R., Stem, C., Swaminathan, V., Brown, M., Johnson, A., PLACCI, G. et al. (2013) Results chains: a tool for conservation action design, management, and evaluation. Ecology and Society, 18, 22, http://dx.doi.org/10.5751/ES-05610-180322.

Maris, V. \& Béchet, A. (2010) From adaptive management to adjustive management: a pragmatic account of biodiversity values. Conservation Biology, 24, 966-973.

Martin, T.G., Nally, S., Burbidge, A.A., Arnall, S., Garnett, S. T., HAYWA RD, M.W. et al. (2012) Acting fast helps avoid extinction. Conservation Letters, 5, 274-280.

McRae, B.H., Dickson, B.G., Keitt, T.H. \& Shah, V.B. (2008) Using circuit theory to model connectivity in ecology, evolution, and conservation. Ecology, 89, 2712-2724. 
McRae, B.H., Shah, V.B. \& Mohapatra, T.K. (2013) Circuitscape 4 User Guide. The Nature Conservancy. Http://www.circuitscape.org/.

Nandy, S., Kushwaha, S.P.S. \& Mukhopadhyay, S. (2007) Monitoring the Chilla-Motichur wildlife corridor using geospatial tools. Journal for Nature Conservation, 15, 237-244.

NOAA (National Oceanic and Atmospheric Administration) (2017) Earth Observation Group (EOG). Http:// ngdc.noaa.gov/eog/ [accessed 15 January 2016].

NTCA (National Tiger Conservation Authority) (2015) Standard Operating Procedure for Active Management Towards Rehabilitation of Tigers from Source Areas at the Landscape Level. Ministry of Environment, Forest, and Climate Change, New Delhi, India.

RaSaily, S.S. (2012) Management Plan of Rajaji National Park, 2012-13 to 2021-2022. Uttarakhand Forest Department, Dehradun, India.

Rathore, H.S. (2015) Response of leopard (Panthera pardus fusca) in varying density of tiger (Panthera tigris tigris) in Rajaji National Park, Uttarakhand. MSc thesis. Saurashtra University, Rajkot, India.

Redpath, S.M., Young, J., Evely, A., Adams, W.M., Sutherland, W.J., Whitehouse, A. et al. (2013) Understanding and managing conservation conflicts. Trends in Ecology \& Evolution, 28, 100-109.

Ross, J.P. (1998) Crocodiles: Status Survey and Conservation Action Plan. IUCN, Gland, Switzerland.

Salafsky, N., Margoluis, R., Redford, K.H. \& Robinson, J.G. (2002) Improving the practice of conservation: a conceptual framework and research agenda for conservation science. Conservation Biology, 16, 1469-1479.

Sanderson, E., Forrest, J., Loucks, C., Ginsberg, J., Dinerstein, E., Seidensticker, J. et al. (2006) Setting Priorities for the Conservation and Recovery of Wild Tigers: 2005-2015. Smithsonian Conservation Biology Institute, Washington, DC, USA.

SAXENA, K.G. (1986) Forest cover changes between proposed Rajaji National Park and Corbett National Park during the period 19721983 for identifying elephant corridors. In Proceedings of the Seminar-Cum-Workshop on Wildlife Habitat Evaluation using Remote Sensing Techniques, pp. 229-237.

Singh, A.K., Easa, P., Kumar, A. \& Menon, V. (2003a) Securing the Chilla-Motichur corridor. In Securing the Chilla-Motichur Corridor: A Status Report (eds V. Menon, P. Easa \& A.J. T. Johnsingh), pp. 36-47. Wildlife Trust of India, New Delhi, India.

Singh, A.K., Easa, P., Menon, V. \& Mookherjee, A. (2003b) Elephant mortality in train accident: a scientific approach to understanding and mitigating this problem in Rajaji National Park. In Securing the Chilla-Motichur Corridor: A Status Report (eds V. Menon, P.K. Easa \& A.J.T. Johnsingh), pp. 48-73. Wildlife Trust of India, New Delhi, India.

SiNGH, A.K. \& GurejA, N. (2001) Elephant conflict issues: two resolution case studies from India. In National Symposium on Elephant Conservation, Management and Research, Rajaji National Park, Uttaranchal, pp. 16-20.

Singh, A.P. \& CHALISGAONKAR, R. (2006) Restoration of Corridors to Facilitate the Movement of Wild Asian Elephants in Rajaji-Corbett Elephant Range, INDIA. Uttarakhand State Irrigation Department, Roorkee, India.

Singh, A.P. \& Sharma, R.C. (2001) Conflicts between linear developments and Asian elephants in sub-Himalayan zone of Uttranchal. In Proceedings of the 2001 International Conference on Ecology and Transportation (eds C. Irwin, P. Garrett \& K.
McDermott), pp. 423-432. Center for Transportation and the Environment, North Carolina State University, Raleigh, USA.

SINGH, K.N. (2002) A strategy for conservation of the habitat of north-western population of Indian elephants. Indian Forester, 128, 1061-1077.

Singh, R., Qureshi, Q., Sankar, K., Krausman, P.R. \& Goyal, S.P. (2013) Use of camera traps to determine dispersal of tigers in semi-arid landscape, western India. Journal of Arid Environments, $98,105-108$.

SinHA, S. (2003) Management and acquisition of the Chilla-Motichur corridor. In Securing the Chilla-Motichur Corridor: A Status Report (eds V. Menon, P.S. Easa \& A.J.T. Johnsingh), pp. 25-33. Wildlife Trust of India, New Delhi, India.

Smith, J.L.D. (1993) The role of dispersal in structuring the Chitwan tiger population. Behaviour, 124, 165-195.

Thapliyal, J. (2017) Tigers relocation at Rajaji reserve after monsoon. The Tribune. Http://www.tribuneindia.com/news/uttarakhand/ tigers-relocation-at-rajaji-reserve-after-monsoon/456554.html [accessed 24 August 2017].

Uniyal, S., Agrawal, S., Rana, M.S. \& Verma, Y.S. (2006) Bibliography on Rajaji National Park, Envis Bulletin: Wildlife and Protected Areas. Wildlife Institute of India, Dehradun, India.

VanderWerf, E.A., Groombridge, J.J., Fretz, J.S. \& Swinnerton, K.J. (2006) Decision analysis to guide recovery of the po'ouli, a critically endangered Hawaiian honeycreeper. Biological Conservation, 129, 383-392.

Wallace, R.L. (1994) The Florida manatee recovery program: uncertain information, uncertain policy. In Endangered Species Recovery: Finding the Lessons, Improving the Process (eds T.W. Clark, R.P. Reading \& A.L. Clark), pp. 131-156. Island Press, Washington, DC, USA.

Wilhere, G.F. (2002) Adaptive management in habitat conservation plans. Conservation Biology, 16, 20-29.

Williams, A.C., Johnsingh, A.J.T. \& Krausman, P.R. (2001) Elephant-human conflicts in Rajaji National Park, northwestern India. Wildlife Society Bulletin, 29, 1097-1104.

Williams, A.C., Johnsingh, A.J.T., Krausman, P.R. \& Qureshi, Q. (2008) Ranging and habitat selection by Asian elephants (Elephas maximus) in Rajaji National Park, north-west India. Journal of the Bombay Natural History Society, 105, 24-33.

\section{Biographical sketches}

Abishek HaRihar has worked on tiger conservation in northern India since 2003 and currently works as a tiger population ecologist, with research interests spanning population ecology, law enforcement monitoring, measuring conservation effectiveness, and conservation decision making. Mousumi Ghosh-Harihar has previously researched the ecological and historical determinants of breeding leaf warblers in the Himalayas. She has also worked on urban birds, human-tiger conflict, and formulating an online photographic datasharing policy. Douglas MacMillan's work focuses on understanding, modelling and evaluating the economic dimensions of environmental change and biodiversity conservation, with special expertise in ecosystem valuation, decision analysis and conflict between people and large carnivores. 